\title{
THE SAFETY PROJECT: SENTINEL-1 FOR THE MANAGEMENT OF GEOLOGICAL RISK
}

\author{
ANNA BARRA ${ }^{1}$, ORIOL MONSERRAT ${ }^{1}$, LORENZO SOLARI $^{2}$, GERARDO HERRERA ${ }^{3}$, \\ CARMEN LOPEZ ${ }^{4}$, ROBERTA ONORI ${ }^{5}$, PAOLA REICHENBACH ${ }^{6}$, ELENA GONZÁLEZ-ALONSO ${ }^{4}$, \\ ROSA MARÍA MATEOS ${ }^{3}$, SILVIA BIANCHINI ${ }^{2} \&$ MICHELE CROSETTO $^{1}$ \\ ${ }^{1}$ Centre Tecnològic de Telecomunicacions de Catalunya (CTTC/CERCA), Spain \\ ${ }^{2}$ University of Firenze, Italy \\ ${ }^{3}$ Instituto Geológico y Minero de España (IGME), Spain \\ ${ }^{4}$ Instituto Geográfico Nacional (IGN), Spain \\ ${ }^{5}$ Italian Civil Protection Department, Italy \\ ${ }^{6}$ Istituto di Ricerca per la Protezione Idrogeologica (IRPI), National Research Council (CNR), Italy
}

\begin{abstract}
SAFETY (Sentinel-1 for geohazards regional monitoring and forecasting - safety.cttc.es) is a two-year research project funded under the ECHO (European Civil Protection and Humanitarian Aid Operations) call "Prevention and preparedness projects in Civil Protection and marine pollution", which started on the 1st January 2016. The mission of the project was to improve the efforts in detecting and mapping geohazards (i.e. landslide, volcanic and subsidence), by assessing their activity and evaluating their impact on built-up areas and infrastructure networks through space-borne radar data. This goal has been achieved through the use of Sentinel-1 DInSAR (Differential Synthetic Aperture Radar Interferometry) derived products and the development of software tools. The most challenging part concerned the semiautomatic generation of derived maps to be easily interpreted and exploited in the geohazard management by the Civil Protection Authorities, which are not usually familiar with DInSAR products. This work provides an overview of the project activities, describing the developed procedure, the main outcomes, and the most significant results obtained over the two test sites of the project: the Canary Islands (Spain) and the Volterra municipality (Italy). The main goal of this work is to present the potentialities of Sentinel-1 interferometry as a regular complementary input for the regional scale risk management.
\end{abstract}

Keywords: SAFETY, Sentinel-1, geohazard, risk, civil protection, DInSAR, monitoring, PSI.

\section{INTRODUCTION}

The characterization and monitoring of the state of activity of geohazards is a fundamental information for the risk analysis and prevention at both local and regional scale. The exploitation of Synthetic Aperture Radar (SAR) images, through the Differential Interferometry (DInSAR) techniques, is particularly suited for the multiscale analysis of ground deformations [1]. DInSAR techniques are based on the exploitation of the phase difference (interferogram) between two radar images, in order to derive ground displacements with millimetre accuracy [2]. In the last 25 years, DInSAR has given a great contribution in the detection and monitoring of geohazards like landslides [3]-[6], subsidence [7]-[12] or volcanos [13]-[17]. Since its first use [18], the application fields of DInSAR have increased a lot because: i) several DInSAR methodologies and processing tools have been developed and ii) a lot of satellite SAR data are available. Regarding the processing methodologies, some examples are: the interferometric analysis [2], [5], [19]; the multiinterferometry analysis [20]-[23] and several implementations of the Persistent Scatterer Interferometry (PSI) technique. A review of all the PSI implementations is available in Tomás et al. [8] and Crosetto et al. [24]. For what concerns the availability of SAR data, an important step forward has been done with the recent satellites Sentinel-1 (S1) A and B, launched respectively in 2014 and 2016 [25] by the European Space Agency. Sentinel-1 
ensures a regular worldwide acquisition, with a high temporal sampling (acquiring an image every six days in Europe), providing free data available to all users, without limitations. Moreover, the acquisition method (Terrain Observation by Progressive Scans (TOPS)) guarantees images covering wide areas $\left(250 \times 250 \mathrm{~km}^{2}\right)$. These characteristics represent an innovation in the use of this technique, allowing accomplishing long term monitoring planning, at a regional scale, in any place of the world. By the way, there is still a gap in in the transition from the almost-exclusive usage of DInSAR by the scientific community or expert technicians, to the wide gamma of potential users that are involved in the risk management activities. The SAFETY project is aimed at both filling this gap and improving the Sentinel-1 data exploitation. The aim of this work is to present the potentialities of Sentinel-1 as a constant regional-to-local scale geohazards monitoring tool and impact assessment, through the methodology developed in SAFETY.

\subsection{Basics of DInSAR}

Synthetic Aperture Radar Differential Interferometry (DInSAR) exploits the phase difference between two SAR images acquired over the same area, in different times (M and S). The phase difference between two SAR images (interferogram) can be used to estimate possible movements of the ground surface occurred in the period between the two acquisition dates. As described by eqn (1), the phase difference $\left(\Delta \varphi_{\text {int }}\right)$ allows to estimate the difference of the satellite-ground distance between the two acquisitions $\left(\mathrm{R}_{\mathrm{M}}-\mathrm{R}_{\mathrm{S}}\right)$. The technique is able to measure the projection on the satellite Line Of Sight (LOS) direction of the real displacement

$$
\begin{gathered}
\Delta \varphi_{\mathrm{int}}=\varphi_{M}-\varphi_{S}=\frac{4 \pi}{\lambda}\left(R_{M}-R_{S}\right), \\
\Delta \varphi_{\mathrm{int}}=\varphi_{m o v}+\varphi_{g e o m}+\varphi_{\text {atmo }}+\varphi_{\text {noise }} .
\end{gathered}
$$

As described by eqn (2), the phase difference $\left(\Delta \varphi_{\text {int }}\right)$ is affected by four main components:

1) The possible ground surface displacement $\left(\Delta \varphi_{\mathrm{mov}}\right)$ : difference of the distance between the satellite and the measured ground point $\left(R_{M}-R_{S}\right)$ due to the ground movement between the two acquisition times;

2) The phase related to the acquisition geometry $\left(\Delta \varphi_{\text {geom }}\right)$ : this is the difference of the signal path due to the different position of the satellite in the two acquisition times.

3) Atmospheric component $\left(\Delta \varphi_{\text {atmo }}\right)$. This component is associated with the atmospheric variability between the two acquisition times.

4) Phase noise $\left(\Delta \varphi_{\text {noise }}\right)$. This component includes different types of noise factors. An example is a change of the surface conditions (e.g. humidity, growing of grass, snow coverage) between the two acquisition times.

Several methods exist in order to extract the displacement component $\left(\Delta \varphi_{\text {mov }}\right)$. When this component is stronger than the others, it can be extracted by the use of only two images, acquired before and after the movement [26], i.e. through the single interferograms analysis [5]. When the targets are movements of lower magnitude, it is necessary to use a stack of images [23], [27] to perform the Advanced Differential Interferometry (A-DInSAR) analysis. The output of an A-DInSAR procedure is a set of spatially distributed measurement points, generally known as Persistent Scatterers (PS). For each point, the mean annual velocity in the observed period and the time series of the deformation are provided. The spatial density of PS depends on several local factors, like the geometry (i.e. the local topography), the surface characteristics (e.g. lithology, humidity, snow presence) and the land cover. 


\subsection{The SAFETY project}

SAFETY is a European project (Sentinel-1 for geohazards regional monitoring and forecasting - safety.cttc.es) funded under the 2015 ECHO (European Civil Protection and Humanitarian Aid Operations) call "Prevention and preparedness projects in Civil Protection and marine pollution". It started on the 1st January 2016 [28] and finished on the 31st December 2017. The aim of SAFETY was to improve the exploitation of Sentinel-1 data for the geohazards monitoring (landslide, volcano and subsidence) and the Civil Protection Authorities' (CPA) activities of risk management at a regional scale. This goal can be divided in two main research lines: a) allowing the full exploitation of Sentinel-1 data for geohazard monitoring through the development of software tools and semi-automatic methodologies; and b) making the DInSAR results feasible to be used by any actor involved in the risk management through the simplification of the results in clear and useful products. The main constraining aspect is the complexity of the DInSAR technique, both in terms of processing the data to extract the movement information and of interpreting the results. For what concerns the second aspect, the interpretation of the DInSAR derived products (like the deformation velocity maps) requires a deep knowledge of the technique and can be misleading for a final user who is not familiar with the DInSAR technique [29], [30]. Usually, the CPAs who manage with geohazard monitoring and management do not have this background knowledge. Moreover, CPAs need maps containing clear and selected useful information.

Resuming in few points, SAFETY addressed the following challenging factors:

1) The under-exploitation of the available data;

2) The geometric limitation of SAR acquisition as the capability of measuring deformation only in the line of sight (LOS) of the satellite;

3) The spatio-temporal noise;

4) The huge amount of information.

Point 1 refers to the huge number of data provided by Sentinel-1 (an image every six days) that can be difficult to manage. SAFETY has produced a software tool, able to process Sentinel-1 data through an approach of the Persistent Scatterer Interferometry chain, developed by the Geomatics Division of CTTC (PSIG) and described in [31]. This developed tool is free and available to all the institutions that support the CPAs activities, allowing them to periodical generate the deformation maps. Moreover, the semi-automatic methodology developed in SAFETY is fast and repeatable, increasing the potential exploitation of Sentinel-1 data. Nevertheless, this point is still open for what concerns the full exploitation of the six day information contained in a single six day temporal baseline interferogram (single interferogram analysis), which is crucial for a near-real time monitoring and for supporting early warning systems (EWS). This aspect will be addressed by the European project U-Geohaz (01/01/2018-31/12/2019), funded under the 2017 ECHO call, which addresses some specific key needs and improvements detected in SAFETY.

Points 2 and 3 are the main misleading aspects. For example, a final user needs to know that a PS without detected movement does not necessarily means that the relative area is stable, and he needs to be able to discriminate the noisier information from the reliable ones.

Point 4 refers to the high number of measurements (PSs) that this technique can provide, making difficult and time consuming the identification of active motions, especially when working at regional scale. The semi-automatic methodology developed in SAFETY deals with the last 3 points: it allows a rapid filtering and extraction of the most significant detected Active Deformation Areas (ADA), by resuming only the key related information and 
attributing a Quality Index (QI) assessing the reliability level of each ADA [32]. Moreover, the developed methodology proposes a way of using the ADA map to derive other maps useful in the risk management activities [9].

\section{METHODOLOGY}

The general flowchart of the developed methodology is presented in Fig. 1. It is thought to be iteratively applied, with a frequency that depends on the monitoring target. The methodology can be divided in the three main blocks explained in the following.

\subsection{Block 1 - processing of Sentinel-1 data}

The processing of Sentinel-1 data allows estimating the annual velocity and the deformation time series (TS) in correspondence of distributed PS, over wide areas: the output of this block is the preliminary surface deformation map (Row Deformation Map).

\subsection{Block 2 - post-processing}

The second block consists in a post-processing of the Row Deformation Map (RDM) in order to simplify the information delivered to the final users. The outputs generated within this block are two: the Deformation Activity Map (DAM) and the Active Deformation Ares map. The first one is derived by a filtering of the noisier and spatially isolated PSs of the RDM, reducing the spatio-temporal noise and thus increasing the readability of the map. The second is the result of a semi-automatic extraction from the DAM of the most significant active areas. This passage implies the extrapolation of a polygonal area from a set of points. An area is considered significant, thus defined as ADA, when it is composed by at least four PSs with velocity of deformation higher than a threshold, so being "active". For each ADA polygon, the most relevant information is resumed (e.g. the mean annual velocity and the accumulated deformation), allowing a rapid and easy regional scale overview of the results. Moreover, a Quality Index (QI) classifies each ADA on the basis of an estimation of its reliability level,

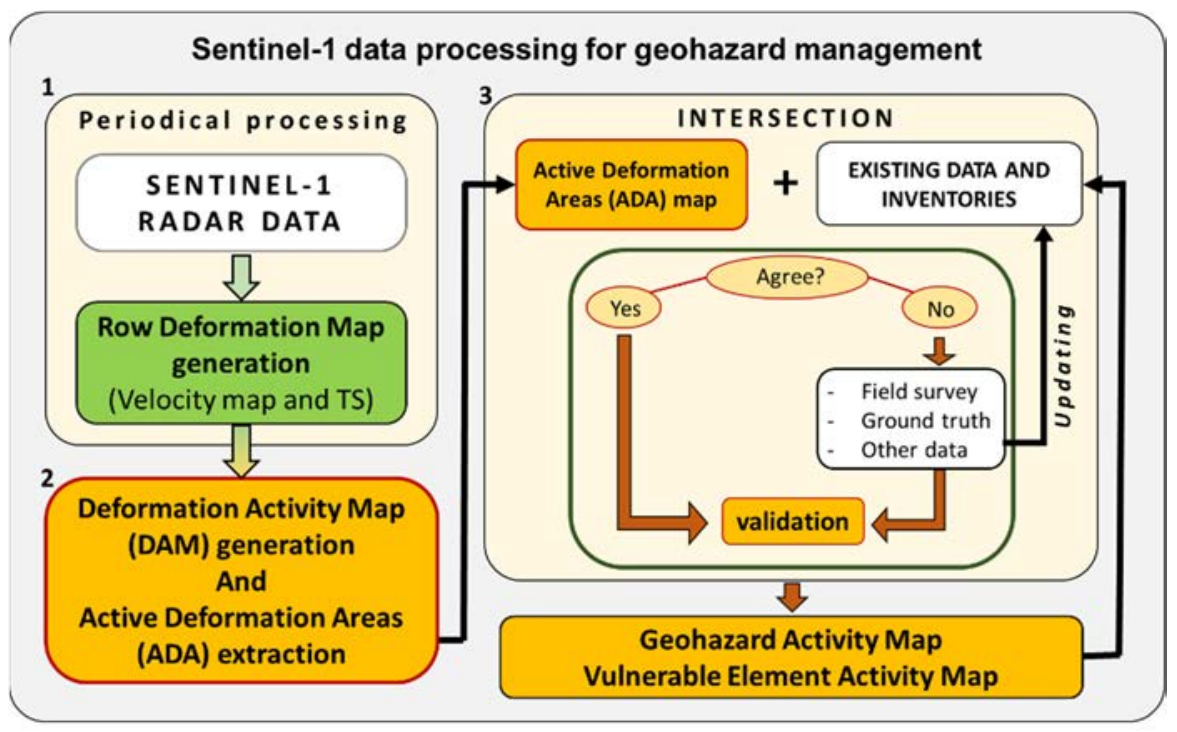

Figure 1: Flowchart of the methodology developed in SAFETY. 
which is a fundamental information for the final users. The ADA extraction can be easily performed in a Geographic Information System (GIS) environment. We refer to Barra et al. [32] for a detailed description of this block.

\subsection{Block 3 - ADA for geohazard management}

This block is a step forward of interpretation and application of the ADA map for the geological risk management in the specific context of each study area. It consists in the intersection of the ADA map with the existing knowledge and data, like inventories or susceptibility maps, in a Geographic Information System (GIS). On one hand, the intersection allows validating the detected ADA, attributing the type of the deformation; on the other hand, this procedure updates the existing data by adding new detected deformations or changing the spatial and temporal activity state of already known phenomena. The interpreted ADA, with the attribution of a geological explanation behind each movement, is one of the output of this block, which is called Geohazard Activity Map (GAM). Then, the intersection of the GAM with the exposed elements (e.g. infrastructures, streets, houses, hospitals) provides the Vulnerable Element Activity Map (VEAM). The VEAM considers only the ADA affecting elements at risk and summarizes, in a visual and direct way, for each portion of the territory (e.g. municipalities, regions, basins), the number of impacting ADA and the emergency level related based on a classification of the affected elements. We refer to Solari et al. [9] for a detailed description of this block.

\section{RESULTS AND APPLICATIONS}

In this section, some results over the test sites of the project are presented with the aim of showing the potentialities of the developed methodology. Then, some examples of the actual application of SAFETY in the risk management will be exposed.

\subsection{Test sites}

The test-sites of SAFETY were Volterra (Tuscany Region, Central Italy) and the Canary Islands (La Gomera, Tenerife and Gran Canaria, Spain). The two locations allowed evaluating the methodology in different environmental conditions considering various scenario of applications. In the Canary Islands the main geohazards are volcanic and rockfalls whereas in the Volterra Municipality are landslides. Moreover, the geo-lithological setting and the land coverage of the two sites determine a very different radar response in terms of coherence.

Canary Islands test site, covering a total land surface of around $4,000 \mathrm{~km}^{2}$, allows testing the regional scale potentialities of the procedure, while Volterra municipality is about $250 \mathrm{~km}^{2}$. For both the test sites, two consecutive iterations of the methodology have been performed in order to test the monitoring potentialities.

\subsection{An overview on the obtained results}

Fig. 2 shows the results of the application of the methodology over Tenerife (Spain). Fig. 2(a) and (b) present the transition between the Row Deformation Map (RDM, Fig. 2(a)), derived by the Sentinel-1 DInSAR processing, to the final Deformation Activity Map (DAM, Fig. 2(b)), after the filtering. Both maps visualize the results in terms of annual LOS velocity estimated in the observed period. Fig. 3(b) shows that the DAM appears less noisy then RDM, this implies a better understanding of the map by the final users. 

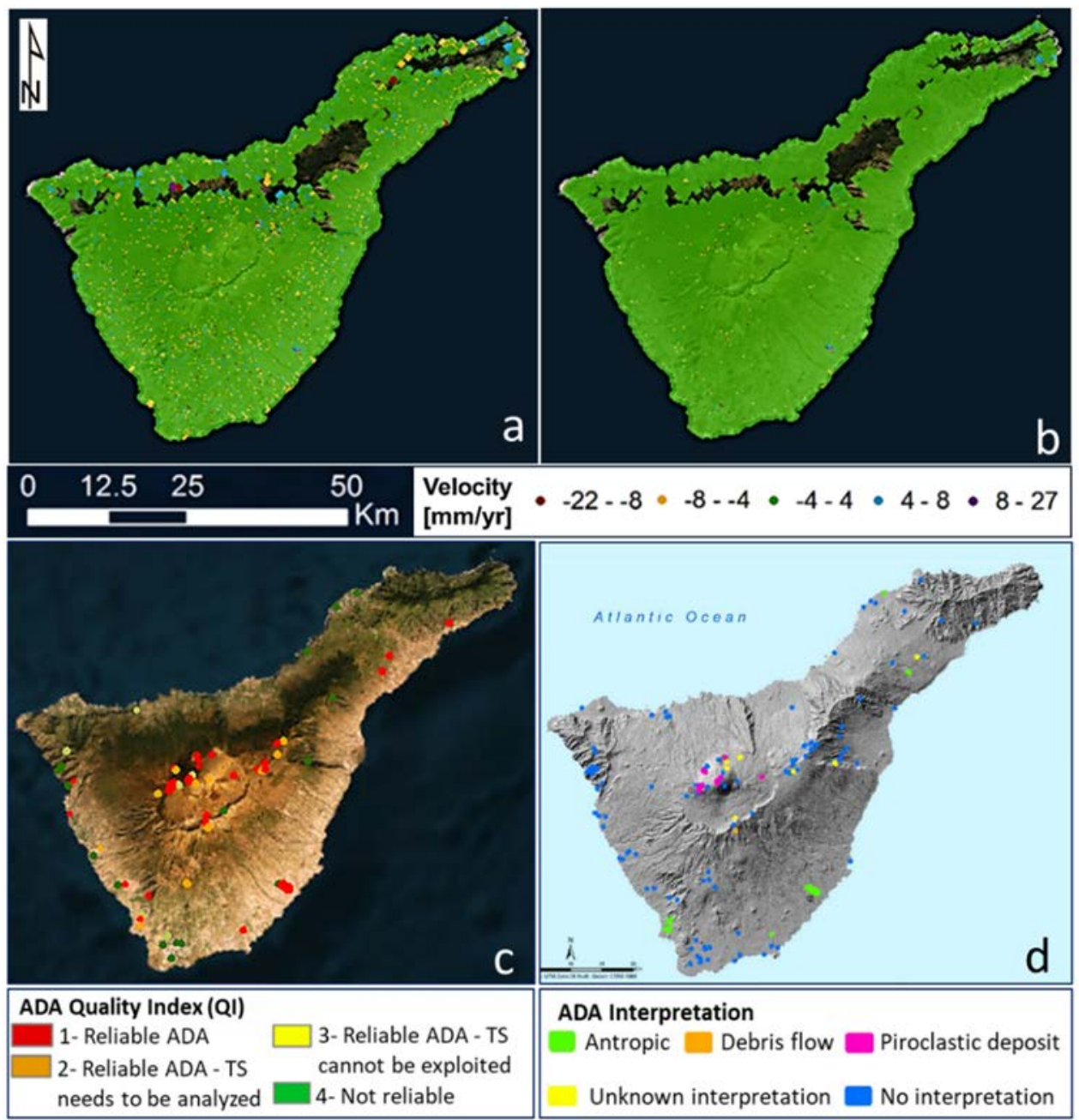

Figure 2: $\quad$ Results of the methodology over Tenerife (Canaries, Spain). (a) The RDM; (b) The DAM; (c) The ADA map; and (d) The interpretation of the ADA.

It is worth to underline that the green points can be stable points as well as moving points, but with a not detectable movement. The zones without PS are usually characterized by low coherence, mainly because of the vegetation coverage or strong changes in time. Fig. 2(c) shows the ADA map, automatically extracted from the DAM [32]. The ADA are classified on the basis of the QI. This figure shows the strong simplification of the ADA map with respect to the DAM. Only in Tenerife, we reduce the information to be interpreted from one million points, in the DAM, to one hundred areas, in the ADA map. Fig. 2(d) presents a Geohazard Activity Map (GAM) that is the result of a preliminary interpretation of the possible geological process behind each deformation area. It has been done through the complementary use of aerial photos, digital elevation models, geological maps and field investigations. Fig. 3 shows an example of VEAM derived by the intersection of the GAM 


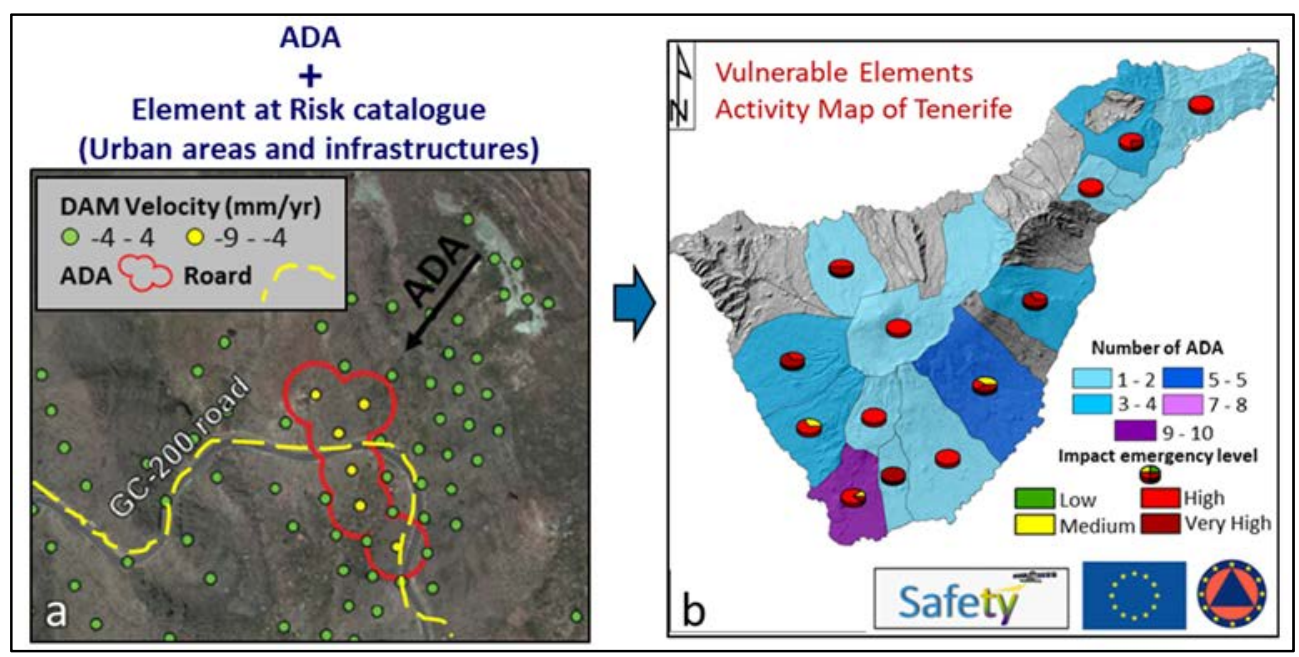

Figure 3: (a) ADA impacting a road; (b) Example of VEAM of Tenerife (Spain).

with an inventory of exposed elements at risk. Fig. 3(a) shows an example of ADA affecting a road (exposed element). The VEAM (Fig. 3(b)) resumes the information of the potential impact that the detected ADA can represent for each territorial unit. In the case of Tenerife, the territorial units are the municipalities. This map is a step forward of simplification, useful for CPAs to redirect resources for further investigation, monitoring efforts or interventions. In Fig. 4 some results over the Volerra city are visualized. This figure aims at presenting the monitoring potentialities through the periodical processing of stacks of images covering different periods. Fig. 4(a) and (b), shows the ADA maps derived by two consecutive iterations of the data processing: the first one covers the period from October 2014 to April 2016, the second one from August 2015 to February 2017. Two ADA affecting the city have been detected. It is possible to see a change of magnitude in the two measured periods: in the Zone 1, no ADA were extracted in the first iteration because of the very low velocity, while in the second iteration a strong acceleration is registered. Then, Fig. 4(c) shows an example of intersection between the ADA map and the existing Landslide Inventory Map (LIM). With a simple intersection, the ADA map allows updating the state of activity of the landslide in the Fontecorrenti district, from dormant to active. Moreover, once the landslide phenomena is attributed to the detected ADA, further analysis over the magnitude (in terms of velocity and volumes) can be performed and, if necessary, a more local scale and focused monitoring can be set up.

\subsection{SAFETY in Civil Protection}

The SAFETY consortium included, as both beneficiaries and final users, the Civil Protections of Italy, Canary Islands and Spain, allowing to direct the SAFETY results in order to fit as better as possible the user requirements and necessities. SAFETY project aimed at providing a long-term infrastructure designed to allow the continuation of the project activities, at least on the two test sites of the project. Activities based on the SAFETY methodology are integrated in the geohazards monitoring activities of different public institutions supporting 


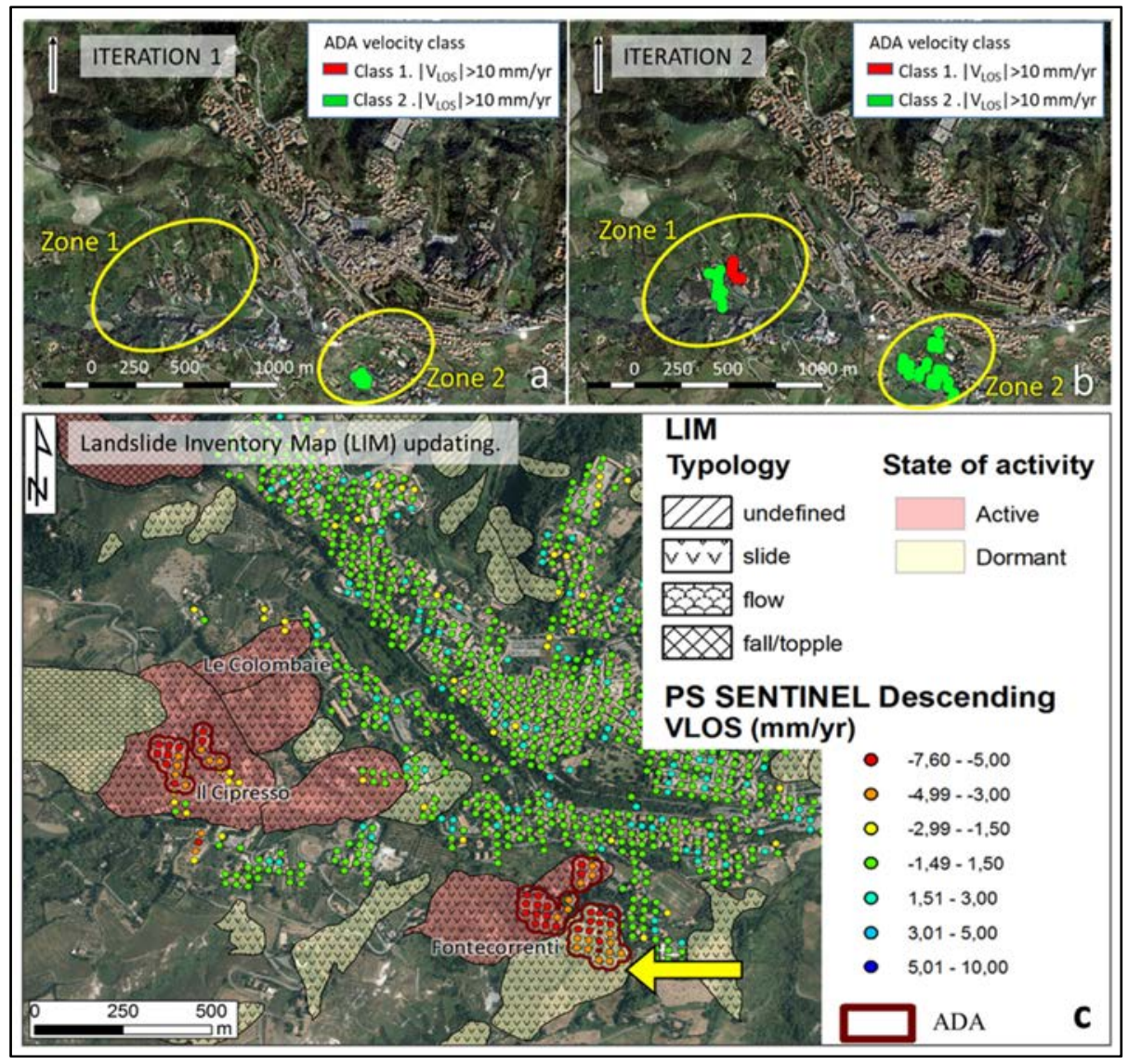

Figure 4: (a) ADA map from the first iteration; (b) ADA map from the second iteration; and (c) Intersection in a GIS environment of the ADA, the DAM velocities and the existing Landslide Inventory (LIM).

the CPAs. The SAFETY software and tools have been modified and automated by the Instituto Geográfico Nacional (IGN), according to their specific needs and requirements. IGN is the geographical institute of Spain and supports the Spanish CPA in the volcanic geohazard monitoring and early warning. SAFETY methodology and products are now integrated into the Volcano Monitoring System (VMS) of IGN (Fig. 5). They use the DInSAR information, together with other data, in order to generate models and to monitor deformations, strengthening their ability to create alarms. The University of Florence (UNIFI), which is a competence centre for the Italian Civil Protection, was also part of the SAFETY consortium. UNIFI is now developing a DInSAR-based monitoring project, named "PS continuous streaming for landslide monitoring and mapping on Tuscany Region (Italy)", that involves the Italian Civil Protection and the Tuscany region hydrogeological risk authorities. In the framework of this agreement, UNIFI is applying and testing a calibrated version of the procedure developed in SAFETY over the Tuscany region, in Italy (Fig. 6). After this agreement, the SAFETY procedure will be potentially implemented by Civil Protection agencies and local authorities to be applied in other regions of Italy. 


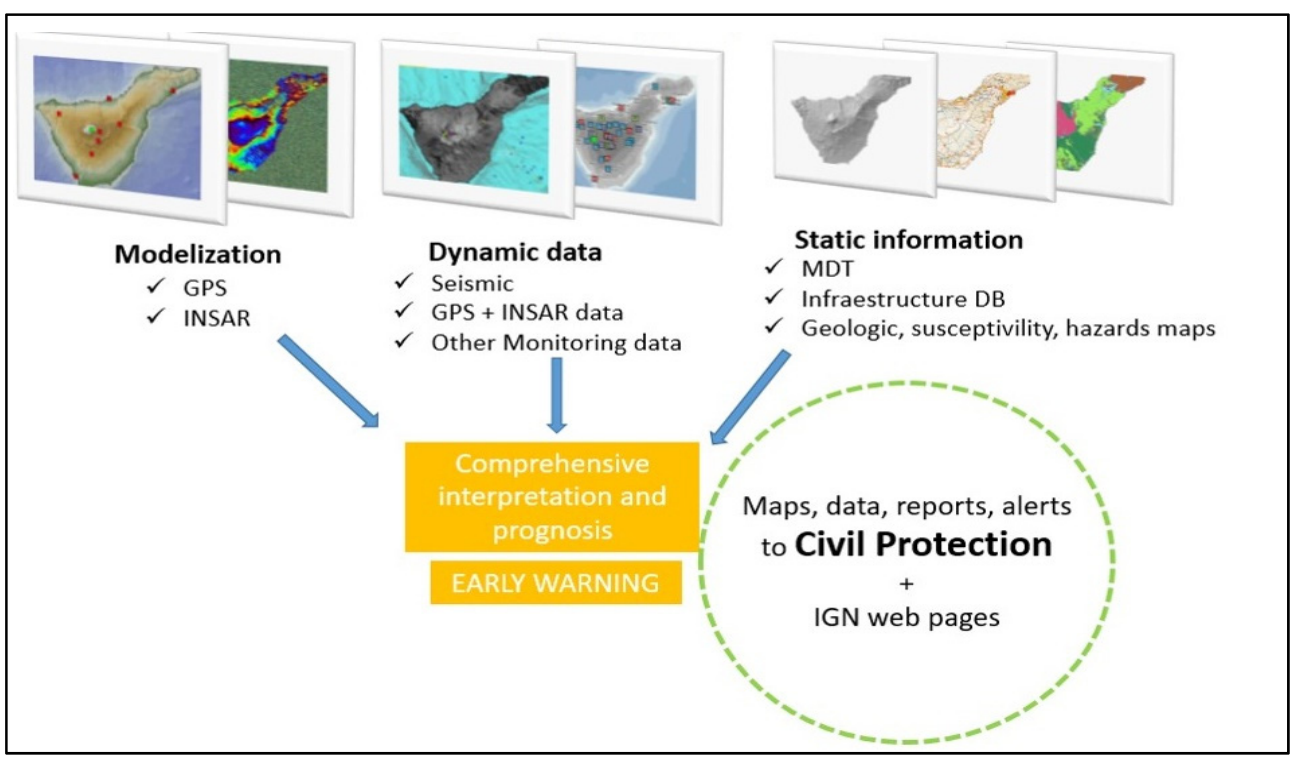

Figure 5: The workflow of the IGN Volcano Monitoring System.

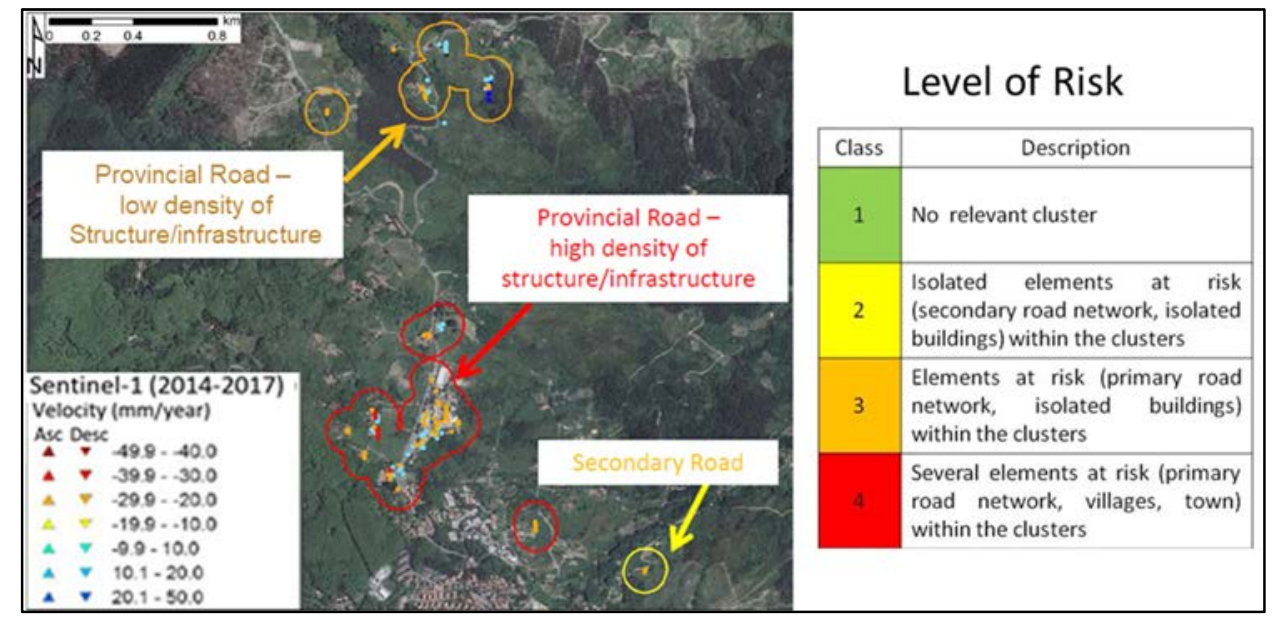

Figure 6: Classification of the ADA based on their impact, in an area of Tuscany Region. Work done in the framework of the project "PS continuous streaming for landslide monitoring and mapping on Tuscany Region (Italy)".

\section{DISCUSSIONS AND CONCLUSIONS}

A proper planning, monitoring, and early warning, are crucial prevention activities in the risk management since they can mitigate the damage caused by natural hazards. The results of SAFETY provide a strong support in those three activities of risk prevention.

A starting point of the risk analysis is the assessment of different scenarios of risk, related to the hazards of the area. A scenario describes the expected event in terms of type, spatial 
dimension and intensity. The SAFETY products provide the spatial distribution of hazardrelated active movements associated to a value of velocity estimated by means of DInSAR analysis, which supports the definition of the intensity of the event. This information allows to describe the actual scenario and to study the hazard in order to assess potential future evolutions of the event (possible future scenarios). In fact, the monitoring capability of the technique represents a strong tool in order to better understand the time-related behaviour of geohazards. Moreover, the described analysis of scenarios, are at the base of the hazard impact analysis. The VEAM map is a starting point of this analysis, assessing the exposed elements affected by the active deformations detected by the DInSAR technique.

In this work, the main activities of the European project SAFETY have been described. The aim of the project was to build a long-term infrastructure to allow an easy use of Sentinel1 satellite data for the detection and monitoring of geohazard-induced ground movements, by the Civil Protection Authorities. With this aim, an open source software tool, for the Sentinel-1 data processing, has been developed. The paper describes the semi-automatic methodology to filter the deformation map (DAM), extract the most significant detected Active Deformation Areas (ADA), and derive secondary products useful for risk management activities. Some results over the two test sites (in Italy and Spain) have been proposed, showing the level of simplification generated by the methodology in the DInSAR results interpretation and exploitation. Nowadays the methodology is being used as a constant monitoring tool by two institutions supporting the Civil Protection risk management activities: in Italy, by the University of Florence, for the landslide risk, and in the Canary Islands (Spain) by the Instituto Geográfico Nacional, for the volcanic risk management. The research activities started in the SAFETY project have been granted and will follow up in the recent project U-Geohaz. U-Geohaz will improve the 6 days repeatability data exploitation and strength the potentiality of the technique as a tool for supporting early warning systems and risk analysis.

\section{ACKNOWLEDGEMENT}

This work has been co-funded by the European Commission, Directorate-General Humanitarian Aid and Civil Protection (ECHO), through the project SAFETY (Ref. ECHO/SUB/2015/718679/Prev02).

\section{REFERENCES}

[1] Fell, R., Corominas, J., Bonnard, C., Cascini, L., Leroi, E. \& Savage, W.Z., Guidelines for landslide susceptibility, hazard and risk zoning for land-use planning. Engineering Geology, 102, pp. 99-111, 2008.

[2] Massonnet, D. \& Feigl, K.L., Radar interferometry and its application to changes in the Earth's surface. Rev. Geophys., 36, pp. 441-500, 1998.

[3] Raspini, F. et al., The contribution of satellite SAR-derived displacement measurements in landslide risk management practices. Natural Hazards, 86(1), pp. 327-351, 2017.

[4] Herrera, G., Tomás, R., López-Sánchez, J.M., Montserrat, O., Cooksley, G. \& Mulas, J., Sistemas radar aplicados a la investigación de subsidencia y movimientos de ladera. Enseñanza de las Ciencias de la Tierra, 17(3), pp. 316-324, 2009.

[5] Barra, A., Monserrat, O., Mazzanti, P., Esposito, C., Crosetto, M. \& Scarascia Mugnozza, G., First insights on the potential of Sentinel-1 for landslides detection. Geomatics, Natural Hazards and Risk, 7(6), pp. 1874-1883, 2016.

[6] Béjar-Pizarro, M. et al., Mapping vulnerable urban areas affected by slow-moving landslides using Sentinel-1 InSAR data. Remote Sensing, 9, p. 876, 2017. 
[7] Abidin, H.Z., Andreas, H., Gumilar, I., Sidiq, T.P. \& Fukuda, Y., Land subsidence in coastal city of Semarang (Indonesia): Characteristics, impacts and causes. Geomatics, Natural Hazards and Risk, 4, pp. 226-240, 2013.

[8] Tomás, R. et al., Radar interferometry techniques for the study of ground subsidence phenomena: A review of practical issues through cases in Spain. Environmental Earth Sciences, 71(1), pp. 163-181, 2014. DOI: doi.org/10.1007/s12665-013-2422-z.

[9] Solari, L. et al., Fast detection of ground motions on vulnerable elements using Sentinel-1 InSAR data. Geomatics, Natural Hazards and Risk, 9(1), pp. 152-174, 2018.

[10] Ferretti, A., Novali, F., Bürgmann, R., Hilley, G. \& Prati, C., InSAR permanent scatterer analysis reveals ups and downs in San Francisco Bay area. Eos, Transactions American Geophysical Union, 85(34), pp. 317-324, 2004.

[11] Zerbini, S., Richter, B., Rocca, F., van Dam, T. \& Matonti, F., A combination of space and terrestrial geodetic techniques to monitor land subsidence: Case study, the Southeastern Po Plain, Italy. J. of Geophysical Research: Solid Earth (1978-2012), 112(B5), 2007.

[12] Béjar-Pizarro, M. et al., Interpolation of GPS and geological data using InSAR deformation maps: Method and application to land subsidence in the Alto Guadalentín Aquifer (SE Spain). Remote Sensing, 8(11), p. 965, 2016.

[13] Massonnet, D. \& Sigmundsson, F., Remote sensing of volcano deformation by radar interferometry from various satellites. Geophysical Monograph, 116, pp. 207-221, 2000.

[14] Peltier, A., Bianchi, M., Kaminski, E., Komorowski, J.C., Rucci, A. \& Staudacher, T., PSInSAR as a new tool to monitor pre-eruptive volcano ground deformation: Validation using GPS measurements on Piton de la Fournaise. Geophys. Res. Lett., 37, pp. 1-5, 2010.

[15] Bonforte, A., Guglielmino, F., Coltelli, M., Ferretti, A. \& Puglisi, G., Structural assessment of Mount Etna volcano from permanent scatterers analysis. Geochem. Geophy. Geosy., 12, pp. 1-19, 2011.

[16] Lagios, E. et al., SqueeSARTM and GPS ground deformation monitoring of Santorini Volcano (1992-2012): Tectonic implications. Tectonophysics, 594, pp. 38-59, 2013.

[17] Di Traglia, F. et al., Lava delta deformation as a proxy for submarine slope instability. Earth and Planetary Science Letters, 488, pp. 46-58, 2018.

[18] Gabriel, A.K., Goldstein, R.M. \& Zebker, H.A., Mapping small elevation changes over large areas: Differential radar interferometry. Journal of Geophysical Research. Solid Earth, 94(B7), pp. 9183-9191, 1989.

[19] Rosen, P.A. et al., Synthetic aperture radar interferometry. Proceedings of the IEEE, 88(3), pp. 333-382, 2000.

[20] Berardino, P., Fornaro, G., Lanari, R. \& Sansosti, E., A new algorithm for surface deformation monitoring based on small baseline differential SAR interferograms. IEEE TGRS, 40(11), pp. 2375-2383, 2002.

[21] Mora, O., Mallorqui, J.J. \& Broquetas, A., Linear and nonlinear terrain deformation maps from a reduced set of interferometric SAR images. IEEE TGRS, 41(10), pp. 2243-2253, 2003.

[22] Biescas, E., Crosetto, M., Agudo, M., Monserrat, O. \& Crippa, B., Two radar interferometric approaches to monitor slow and fast land deformation. Journal of Surveying Engineering, 133(2), pp. 66-71, 2007. 
[23] Crosetto, M., Monserrat, O., Cuevas, M. \& Crippa, B., Spaceborne differential SAR interferometry: Data analysis tools for deformation measurement. Remote Sensing, 3(2), pp. 305-318, 2011.

[24] Crosetto, M., Monserrat, O., Cuevas-González, M., Devanthéry, N. \& Crippa, B., Persistent scatterer interferometry: A review. ISPRS Journal of Photogrammetry and Remote Sensing, 115, pp. 78-89, 2016.

[25] Rucci, A., Ferretti, A., Monti Guarnieri, A. \& Rocca, F., Sentinel-1 SAR interferometry applications: The outlook for sub millimeter measurements. Remote Sensing of Environment, 120, pp. 156-163, 2012.

[26] Hanssen, R., Radar Interferometry, Kluwer Academic Publishers: Dordrecht, 2001.

[27] Hooper, A., Zebker, H., Segall, P. \& Kampes, B., A new method for measuring deformation on volcanoes and other natural terrains using InSAR persistent scatterers. Geophysical Research Letters, 31(23), 2004.

[28] Monserrat, O., Herrera, G., Barra, A., Sarro, R., López, C. \& Pascual, G., El proyecto SAFETY: uso de datos Sentinel-1 para la monitorización a escala regional de riesgos geológicos. Reducción del riesgo de desastres (Protección Civil Española), 2017. DOI: doi.org/10.5281/zenodo.1158579.

[29] Ferretti, A., Monti-Guarnieri, A., Prati, C., Rocca, F. \& Massonet, D., InSAR principles-guidelines for SAR interferometry processing and interpretation, 19, 2007.

[30] Notti, D. et al., A user-oriented methodology for DInSAR time series analysis and interpretation: Landslides and subsidence case studies. Pure and Applied Geophysics, 172(11), pp. 3081-3105, 2015.

[31] Devanthéry, N., Crosetto, M., Monserrat, O., Cuevas-González, M. \& Crippa, B., An approach to Persistent Scatterer Interferometry. Remote Sens., 6, pp. 6662-6679, 2014.

[32] Barra, A. et al., A methodology to detect and update active deformation areas based on Sentinel-1 SAR images. Remote Sensing, 9(10), p. 1002, 2017. 